\title{
Armington Product Variety Growth in Small versus Large Countries
}

\author{
Peter Egger $^{a}$, Martin Gassebner $^{\mathrm{b}}$ and Andrea Lassmann ${ }^{c}$
}

JEL-Classification: C43, F14

Keywords: product variety, Armington differentiation model

\section{Introduction}

The key mechanism behind gains from trade in New Trade Theory type models with a preference structure à la Dixit and Stiglitz (1977) is associated with gains from variety. Accordingly, a recent strand in empirical international economics focuses on the quantification of those gains (see Broda and WEINSTEIN, 2006). An issue which is at the heart of this line of work is the measurement of the expansion or contraction of the set of varieties a country trades. Essentially, the literature proposes two possible routes for measurement which rely on alternative choices of the base to define a common set of goods in any two periods of time: either, one chooses an individual reference country or a group of reference countries and determines the products which both a country of interest and the reference country (or country bloc) trade and the ones which only the country of interest trades in one of the years (see Feenstra, 1994; Feenstra and Kee, 2008); the other option is to choose all common products traded by a country in any year the researcher is interested in and determine the products which the country of interest traded in every year of interest and which ones it started or stopped trading (see Hummels and Klenow, 2005; Broda and Weinstein, 2006). Either approach leads to the same measure of of the extensive margin of trade as long as the reference year or country, respectively, is constant across the units of observation and the Armington (1969) definition of an import variety is used.

a KOF Swiss Economic Institute, ETH Zurich, CEPR, CESifo; email: egger@kof.ethz.ch.

b KOF Swiss Economic Institute, ETH Zurich; email: gassebner@kof.ethz.ch.

c Corresponding author; KOF Swiss Economic Institute, ETH Zurich; email: lassmann@kof. ethz.ch. 
Our research aims at shedding light on the magnitude of change in the extensive export country margin across two decades (1980-2000) for three rather heterogeneous importers: Japan, Switzerland, and the United States. In what follows, we assume that variety at the trade product category level is determined by ARMINGTON (1969) differentiation of one and the same good according to its country of origin. Broadly speaking, an increase in variety in this setting reflects an expansion of the set of exporting countries a chosen economy imports a particular good from. We quantify changes in the Armington margins for each 4-digit product category of the Standard International Trade Classification (SITC), Revision 2. It turns out that the variation in the change of the extensive margin is huge across products. Moreover, we document a systematic pattern in some of the moments of the distribution of Armington variety which is correlated with country size.

\section{Two Ways of Measuring the Change in Armington Import Variety}

\subsection{Measuring the Change in Armington Import Variety à la Feenstra (1994)}

Feenstra (1994) suggests determining the common bundle of goods traded in two periods. Let us refer to an individual product - in our case, one of the 4-digit categories of the Standard International Trade Classification (SITC), Revision $2-$ by index $p$. Furthermore, let us use indices $e=1, \ldots, N$ and $i$ to refer to exporter and importer countries (i.e., $N$ is the total number of countries in the world economy). In an Armington (1969) model, products may be viewed as distinct goods or sectors while they are horizontally differentiated by country of origin (i.e., exporters). Hence, an increase in the number of countries a product is imported from over time is then associated with variety growth in the Armington sense. Let us focus on the years 1980 and 2000 and define the set of all exporters country $i$ imports good $p$ from in year $t$ as $I_{i, p, t}$. For each 4-digit product $p$, denote the set of goods $p$ imported from a given exporter $e$ in both years as $I_{i, p} \equiv I_{i, p, 1980} \cap I_{i, p, 2000}$. Hence, goods in the set $I_{i, p}$ display positive import values of product $p$, imported by country $i$, in years 1980 and 2000 for the same subset of exporters so that $m_{i, e, p, 1980}>0$ and $m_{i, e, p, 2000}>0$ for all exporters $e \in I_{i, p}$ (in general $m_{i, e, p, t}$ denotes nominal bilateral imports of product $p$ by $i$ from $e$ in year $t$ ). Notice that the common set $I_{i, p}$ is time-invariant.

Then, we may define a measure of the change in the extensive margin - i.e., in Armington variety - of imports by country $i$ in product category $p$ between years 1980 and 2000, following Feenstra (1994). For this, define 


$$
\lambda_{i, p, t} \equiv \frac{\sum_{e \in I_{i, p, t}} m_{i, e, p, t}}{\sum_{e \in I_{i, p}} m_{i, e, p, t}} \in[1, \infty),
$$

where $\lambda_{i, p, t}$ measures the ratio of total imports of country $i$ in product category $p$ and year $t$,

$$
\sum_{e \in I_{i, p, t}} m_{i, e, p, t},
$$

which exhibits time variation and

$$
\sum_{e \in I_{i, p}} m_{i, e, p, t}
$$

which is time-invariant. Notice that a larger absolute difference $\left|\lambda_{t}-1\right|$ indicates a greater change in product variety over time. Of course, $\left.\left(\lambda_{i, p, 1980}-1\right)<1\right)$ implies $\left.\left(\lambda_{i, p, 2000}-1\right)>1\right)$, by construction. A compact measure of Armington import variety change following Feenstra (1994) is

$$
\Lambda_{i, p, 1980-2000} \equiv \frac{\lambda_{i, p, 2000}}{\lambda_{i, p, 1980}} \in[0, \infty),
$$

where $0 \leq \Lambda_{i, p, 1980-2000}<1$ indicates a reduction in Armington import variety between 1980 and 2000 and $\Lambda_{i, p, 1980-2000}>1$ reflects an increase in import variety over time.

\subsection{Measuring the Change in Armington Import Variety à la Hummels and Klenow (2005) or Feenstra and Kee (2008)}

Hummels and Klenow (2005) as well as Feenstra and Kee (2008) suggest determining product variety relative to a constant reference country (or a country bloc such as the rest of the world). While neither Hummels and KLENOw (2005) nor Feenstra and KeE (2008) focus on Armington differentiation, their concept of determining product variety is also applicable to an Armington model.

Let us discuss the framework by introducing only a minimum of additional notation as follows. In particular, let us introduce superscript $r$ to denote an arbitrary individual reference country or a bloc of reference countries. As 
before, denote the set of all exporters country $i$ imports good $p$ from in year $t$ as $I_{i, p, t}$. For each 4-digit product $p$, denote the set of products $p$ imported from both exporter $e$ and reference country $r$ in both 1980 and 2000 as $I_{i, p}^{r} \equiv I_{i, p, 1980} \cap I_{r, p, 1980} \cap I_{i, p, 2000} \cap I_{r, p, 2000}$. Hence, nominal import values of product $p$ in the set $I_{i, p}^{r}$ are positive for both countries $i$ and $r$ in years 1980 and 2000 for the same subset of exporters so that not only $m_{i, e, p, 1980}>0$ and $m_{i, e, p, 2000}>0$ but also $m_{r, e, p, 1980}>0$ and $m_{r e, p, 2000}>0$ for all exporters $e \in I_{i, p}^{r}$. Again, the common set $I_{i, p}^{r}$ is time-invariant, as was $I_{i, p}$ in the previous subsection.

A measure of the change in Armington import variety by country $i$ relative to reference country $r$ in product category $p$ between years 1980 and 2000 is, therefore, given by

$$
\lambda_{i, p, t}^{r} \equiv \frac{\sum_{e \in I_{i, p, t}} m_{i, e, p, t}}{\sum_{e \in I_{i, p}^{r}} m_{i, e, p, t}} \in[1, \infty),
$$

where $\lambda_{i, p, t}^{r}$ measures the ratio of total imports of country $i$ in product category $p$ and year $t$,

$$
\sum_{e \in I_{i, p, t}} m_{i, e, p, t},
$$

which exhibits time variation, to

$$
\sum_{e \in I_{i, p}^{r}} m_{i, e, p, t}
$$

which is time-invariant. As before, a larger absolute difference $\left|\lambda_{t}^{r}-1\right|$ indicates a greater change in product variety over time, but now measured as compared to reference country $r$. The corresponding compact measure of Armington import variety change in the spirit of Feenstra (1994) is

$$
\Lambda_{i, p, 1980-2000}^{r} \equiv \frac{\lambda_{i, p, 2000}^{r}}{\lambda_{i, p, 1980}^{r}} \in[0, \infty) .
$$

Again, $0 \leq \Lambda_{i, p, 1980-2000}<1$ indicates a reduction in Armington import variety between 1980 and 2000 and $\Lambda_{i, p, 1980-2000}>1$ reflects an increase in import variety over time. Since 


$$
\sum_{e \in I_{i, p}^{r}} m_{i, e, p, t}
$$

is time-invariant in (4) as was

$$
\sum_{e \in I_{i, p}} m_{i, e, p, t}
$$

in (2),

$$
\Lambda_{i, p, 1980-2000}=\Lambda_{i, p, 1980-2000}^{r}
$$

Hence, when the reference period or country is fixed both approaches yield the same result for an Armington differentiation.

\section{Calculating Armington Import Variety Change for Japan, Switzerland, and the United States}

Let us apply the concepts discussed in the previous section to three import countries, Japan, Switzerland, and the United States.

\subsection{Data}

We use panel data on bilateral imports in nominal U.S. dollars at the 4-digit level of the Standard International Trade Classification (SITC), Revision 2, of the United Nations' Comtrade Database for the years 1980 and 2000. After excluding all exporter countries which are not included in the database for both years of interest, we are left with a sample which is described by Table $1 .{ }^{1}$

In the upper bloc of Table 1, we provide details on the number of product codes and exporter countries for which positive trade flows are reported for any of the three importers of interest in 1980 and 2000, respectively. At the center of Table 1, we provide information about the number of product lines in 1980 and 2000 for the three economies of interest, and at the bottom of the table, we give the number of product-line-exporter dyads which data are available for. For each

1 For instance, this is the case for Czechoslovakia, the German Democratic Republic, or the Soviet Union which do not exist anymore by the year 2000 but also for (unified) Germany or the successor countries of the Soviet Union which did not yet exist as political entities in 1980. 
Table 1: Imports of Japan, Switzerland and the United States, 1980-2000

\begin{tabular}{lrrr}
\hline Statistic & Japan & Switzerland & USA \\
\hline Total number of exporters & & & \\
in 1980 & 76 & 71 & 78 \\
in 2000 & 153 & 174 & 158 \\
Common set of exporters $\left(I_{i, p, 1980} \cap I_{i, p, 2000}\right)$ & 47 & 42 & 56 \\
\hline Total number of 4-digit product lines & & & \\
in 1980 & 776 & 776 & 777 \\
in 2000 & 751 & 771 & 779 \\
Common set of product lines $\left(I_{i, p, 1980} \cap I_{i, p, 2000}\right)$ & 757 & 758 \\
\hline Total number of observations & 10,631 & 10,961 & 14,457 \\
in 1980 & 20,810 & 19,908 & 35,954 \\
in 2000 & 7,123 & 6,945 & 10,228 \\
Common set $\left(I_{i, p, 1980} \cap I_{i, p, 2000}\right)$ & & & \\
\hline
\end{tabular}

Note: This table is based on the 4-digit level of the Standard International Trade Classification (SITC), Revision 2, of the United Nations' Comtrade Database for the years 1980 and 2000.

level we also report the common set for 1980 and 2000 in addition to the values for the two years.

Regarding the number of exporting countries we observe that in 1980 the numbers are rather similar for the three countries we analyze. While this remains true - at a higher level - for Japan and the U.S., Switzerland has a significantly higher number of export partners in 2000. In contrast the common set of exporters is the highest in the U.S. With respect to the number of product lines all three countries behave pretty similar over the period in question. Concerning the total number of observations Japan and Switzerland behave similar while the U.S. is substantially larger in both periods.

\subsection{Results and Discussion}

Based on the data in Table 1, let us now calculate $\lambda_{i, p, t}$ as in (1) and, ultimately, $\Lambda_{i, p, 1980-2000}$ as in (2) for Japan, Switzerland, and the United States. The results of this exercise is reported in Table 2. 
Table 2: Estimates of Armington Variety $\Lambda_{i, p, 1980-2000}$ of Japan, Switzerland and the United States, 1980-2000

\begin{tabular}{lrcc}
\hline Moments of $\Lambda_{i, p, 1980-2000}$ & Japan & Switzerland & USA \\
\hline Minimum & 0.000 & 0.003 & 0.005 \\
1st percentile & 0.090 & 0.065 & 0.066 \\
5th percentile & 0.403 & 0.345 & 0.455 \\
10th percentile & 0.698 & 0.516 & 0.826 \\
25th percentile & 1.075 & 0.799 & 1.130 \\
50th percentile & 1.483 & 1.189 & 1.625 \\
75th percentile & 2.986 & 1.824 & 2.653 \\
90th percentile & 8.264 & 4.224 & 8.521 \\
95th percentile & 21.165 & 10.155 & 35.433 \\
99th percentile & 179.43 & 119.60 & $1,543.3$ \\
Maximum & $2,378.9$ & 930.23 & 252,307 \\
\hline Mean & 12.99 & 6.78 & 531.85 \\
Variance & $11,233.60$ & $2,233.40$ & $9.65 \mathrm{E}+07$ \\
\hline
\end{tabular}

Note: This table is based on the 4-digit level of the Standard International Trade Classification (SITC), Revision 2, of the United Nations' Comtrade Database for the years 1980 and 2000.

The findings may be discussed as follows. First of all, there is an enormous variation in $\Lambda_{i, p, 1980-2000}$ across products $p$ for any of the economies. While the minimum level of $\Lambda_{i, p, 1980-2000}$ across products is not too different from zero for any of the three importers, the maximum value varies dramatically. The latter is also reflected in an enormous variation of the maximum of $\Lambda_{i, p, 1980-2000}$ across the three importers. It turns out that a few large outliers in the distribution of $\Lambda_{i, p, 1980-2000}$ in any of the three economies have a strong impact on the average and the variance of $\Lambda_{i, p, 1980-2000}$. This effect is particularly pronounced for the United States. These outliers are responsible for the fact that there is no obvious pattern in the average, the variance, and the maximum of $\Lambda_{i, p, 1980-2000}$ across economies.

With outliers, it is preferable to consider the median instead of the average of $\Lambda_{i, p, 1980-2000}$ across products. It happens that the median value of $\Lambda_{i, p, 1980-2000}$ is obviously correlated with the pattern of economic size across importer countries. 
In short, $\Lambda_{i, p, 1980-2000}$ is bigger in larger countries than in smaller ones. ${ }^{2}$ Hence, Armington product variety expansion is positively correlated with (economic) country size in Table 2.

\section{Conclusions}

Recent work in international economics provides insights into the measurement of product variety change - i.e., the change at the extensive margin of trade and its consequences for a country's welfare. In such work, the measurement of product variety change is typically taken as given. There is evidence that product variety change is the main source of gains from trade (see Hummels and Klenow, 2005; and Broda and Weinstein, 2006). However, little is known as to what determines product variety growth, e.g., from an Armington perspective as here, and what we can subsequently learn for the inclination of countries, depending on their characteristics, towards trade liberalization.

Results in this paper shed first light on a possible nexus between Armingtontype product variety change (i.e., product diversity by virtue of country of origin) and economic size of countries. Our future research will venture to provide an answer to the question about the key determinants of product variety and as to the heterogeneous consequences of trade liberalization across countries.

\section{References}

Armington, Paul S. (1969), "A Theory of Demand for Products Distinguished by Place of Origin", IMF Staff Papers 16 (1), pp. 159-178.

Broda, Christian, and David E. Weinstein (2006), "Globalization and the Gains from Variety”, Quarterly Journal of Economics 121 (2), pp. 541-585.

Dixit, Avinash K., and Joseph E. Stiglitz (1977), "Monopolistic Competition and Optimum Product Diversity", American Economic Review 67 (3), pp. 297-308.

Feenstra, Robert C. (1994), "New Product Varieties and the Measurement of International Prices”, American Economic Review 84 (1), pp. 157-177.

2 We note, however, that Germany is missing in our dataset. It is the largest trading partner of Switzerland while also playing a significant role both for the USA and Japan. 
Feenstra, Robert C., and Hiau Looi Kee (2008), "Export Variety and Country Productivity: Estimating the Monopolistic Competition Model with Endogenous Productivity", Journal of International Economics 74 (2), pp. 500-518.

Hummels, David, and Peter Klenow (2005), "The Variety and Quality of a Nation's Exports”, American Economic Review 95 (3), pp.704-723. 